\title{
ASSOCIATION BETWEEN JOB STRAIN (HIGH DEMAND-LOW CONTROL) AND CARDIOVASCULAR DISEASE RISK FACTORS AMONG PETROCHEMICAL INDUSTRY WORKERS
}

\author{
SIAMAK POORABDIAN ${ }^{1}$, AMIR HOSSEIN MIRLOHI ${ }^{2}$, EHSAN HABIBI ${ }^{3}$, \\ and MAHNAZ SHAKERIAN ${ }^{4}$ \\ ${ }^{1}$ Esfahan University of Medical Sciences, Esfahan, Iran \\ Department of Occupational Health, School of Hygiene \\ ${ }^{2}$ Esfahan University of Medical Sciences, Esfahan, Iran \\ Occupational Doctor, Salamat Gostar Apadana Company \\ ${ }^{3}$ Esfahan University of Medical Sciences, Esfahan, Iran \\ Occupational Health and Ergonomics, Department of Occupational Health, School of Hygiene \\ ${ }^{4}$ Esfahan University of Medical Sciences, Esfahan, Iran \\ Occupational Hygiene, Department of Occupational Health, School of Hygiene
}

\begin{abstract}
Objective: One of the practical models for assessment of stressful working conditions due to job strain is "job demand and control" or Karasek's job strain model. This model explains how adverse physical and psychological effects including cardiovascular disease risk factors can be established due to high work demand. The aim was to investigate how certain cardiovascular risk factors including body mass index (BMI), heart rate, blood pressure, serum total cholesterol levels, and cigarette smoking are associated with job demand and control in workers. Materials and Methods: In this cohort study, 500 subjects completed "job demand and control" questionnaires. Factor analysis method was used in order to specify the most important "job demand and control" questions. Health check-up records of the workers were applied to extract data about cardiovascular disease risk factors. Ultimately, hypothesis testing, based on Eta, was used to assess the relationship between separated working groups and cardiovascular risk factors (hypertension and serum total cholesterol level). Results: A significant relationship was found between the job demand-control model and cardiovascular risk factors. In terms of chisquared test results, the highest value was assessed for heart rate $\left(\mathrm{Chi}^{2}=145.078\right)$. The corresponding results for smoking and BMI were $\mathrm{Chi}^{2}=85.652$ and $\mathrm{Chi}^{2}=30.941$, respectively. Subsequently, Eta result for total cholesterol was 0.469, followed by hypertension equaling 0.684 . Moreover, there was a significant difference between cardiovascular risk factors and job demand-control profiles among different working groups including the operational group, repairing group and servicing group. Conclusion: Job control and demand are significantly related to heart disease risk factors including hypertension, hyperlipidemia, and cigarette smoking.
\end{abstract}

Key words:

Job demand, Job control, Job strain, Cardiovascular risk factors

Received: September 12, 2012. Accepted: July 16, 2013.

Corresponding author: A.H. Mirlohi, No 17, Siami Alley, Satarkhan Ave., Tohid Sq., P.O. Box: 13185-1678, Tehran, Iran (e-mail: swt_f@yahoo.com). 


\section{INTRODUCTION}

"Job strain" is defined as the situation where one has high job demands combined with low control or decision latitude at work. While a great deal of research has been done to recognize harmful physical agents in the workplace, research on potentially harmful psychosocial risk factors in occupational medicine seems insufficient. In connection with the global economic changes which have been taken into consideration in order to build a safer workplace with fewer workers and more production, psychosocial risk factors may have an even more profound effect compared to physical hazards in the development of diseases in the future generations of workers.

One of the psychological risk models which has been extensively studied is the "job strain" model introduced by Karasek [1,2]. This model measures exposure to psychological and physical work demands, and decision latitude or control. Recent additions to this model include subscales measuring social support and job security, accounting for additional aspects of the workplace context [1]. Studies have shown that high levels of job strain can affect the occurrence of psychological pressures [2-5] as well as cardiovascular diseases [6,7]. However, previous studies did not report consistent results regarding which aspects of this model (i.e. demand, control, interaction between high demand and low control, or job strain) have the greatest impact on workers' health condition.

The Job Demand-Control (-Support) Model has been used in numerous studies to identify the relationship between job strain and health outcomes. In this model, both physical and psychological demands are considered. However, in conceptualizing situations of high job strain, psychological demands are important factors. Decision latitude (control) has components of decision authority and skill discretion. Decision latitude and its interaction with psychological demands define jobs falling under one of four quadrants: high strain, low strain, passive, and active jobs [1]. Situations of low control and high strain in particular are hypothesized to have the strongest effects on health outcomes including cardiovascular diseases [8].

The highest risks have been found in studies using selfratings on the demand, control and support factors; while ratings based on broad occupational titles have had less effect $[9,10]$.

Cardiovascular diseases (CVD) make the most common cause of mortality in the United States (35.2\% of all deaths in 2005). In spite of the recognition of risk factors, there remains unexplained variability in cardiovascular disease occurrence [11]. CVD risk factors have been found to be related to job strain, which is defined as high levels of psychological demand combined with low levels of control at work [12].

The aim of this cohort study was to determine harmful psychosocial factors such as job demands and decision latitude in the workplace and their association with CVD risk factors amongst a sample of petrochemical personnel.

\section{MATERIALS AND METHODS}

\section{Study population}

The study population of this cohort study consisted of male personnel at a petrochemical plant in Iran. The inclusion criteria were having 2-year work experience and health benefits eligibility prior to and during the enrollment into the study. Based on the prior 2-year history of health benefit claims, the following cohorts were formed.

The Ischemic Heart Disease-free Cohort Inclusion Criteria were as follows: being free from any health claims diagnosis of ischemic heart disease for the full 2 years prior to being qualified into the study. At the time of the study, 1125 persons were working at the examined plant. Based on the statistical formula presented below, 500 eligible male workers (exploitation department: 85 cases, 
repair department: 205 cases, and service department: 210 cases) were entered into the study:

$$
n=\frac{\left(Z_{1}+Z_{2}\right)^{2}\left(1-r^{2}\right)}{r^{2}}+2
$$

where:

$\mathrm{n}$ - sample size,

$\mathrm{Z}_{1}$ - confidence interval $(\mathrm{CI})$,

$\mathrm{Z}_{2}$-statistical power (\%),

$r$ - correlation coefficient.

With the confidence level $\left(Z_{1}\right)$ of $95 \%$ and power of $\left(Z_{2}\right) 80 \%$, r was an approximation of the correlation coefficient between job strain and CVD risk factors such as hypertension, smoking, BMI, etc.

The target population for this retrospective cohort study was 500 randomly selected male petrochemical industry employees.

Employees with 2 years of employment and health benefit enrollment were eligible to contribute person-time to the study.

Disease-free cohorts were formed for each outcome, consisting only of the participants with no prior history concerning the outcome of interest. The aims of the study were evaluated from the data available over 2 years, from December 2007 through December 2009.

Psychological demands, decision latitude (control) and their combined effects as job strain (presence of high demand and low control) were measured in the population using a series of questionnaires based on Karasek's Job Demand-Control Model [2]. These questions were the same as those used in the Wall, Jacson \& Mularkey study (1996) 24 questions: 10 questions were related to Job Control and 14 questions were related to job demands [13].

At first, factor analysis method was used in order to specify the most important job demand and control questions. Then, the chi-squared test was applied in order to assess the possible relationship between the separated working groups in petrochemical industry, job demand and control, and some data related to individual demographic variables. Ultimately, hypothesis testing, based on Eta, was used to assess the relationship between the separated working groups and cardiovascular risk factors (hypertension and total cholesterol). The $\mathrm{Chi}^{2}$ test was applied for other risk factors. The study is a retrospective cohort study of the effects of job strain and cardiovascular outcomes.

\section{Demographic information}

Basic demographic information related to the date of birth, job grade, job title, marital status, and education was obtained from administrative databases.

\section{Exposure assessment: Job Demand and Control Measures}

Demand and control as identified in the Job DemandControl Model [1] were measured using items on job demand and control from certain questionnaires.

\section{Risk factor information}

The participants' physical health histories are available via information provided in the administrative health claims data. Data collected for the IHD-free cohort included the presence of hypertension. Additional health history Data were available from some plant occupational health clinics, offering data on smoking, blood pressure, height, weight, and total cholesterol levels. Smoking history was available from health risk behavior information previously collected and entered into a database for nearly half of the employees. Data included the smoking history, length, frequency and amount of smoking or tobacco use.

Using auscultatoric devices (including a mercury-based sphygmomanometer and a stethoscope) we determined the blood pressure by monitoring Korotkoff sounds. An inflatable cuff was placed around the upper arm, at roughly the same vertical height as the heart. It is highly reliable and accurate in most of the cases. The cuff was fitted and inflated by hand until the brachial artery was completely 
occluded (about $30 \mathrm{mmHg}$ above the systolic pressure). Necessary instructions before the measurement were given to the workers who should be relaxed and refrain from physical activities and caffeine consumption before the examination.

Factor analysis was conducted for determining the most important questions of the questionnaire related to job demand and control. The factor of "high demand/low control" or "work strain", as a variable, was also coded as high, medium, and low.

The $\mathrm{Chi}^{2}$ test and the hypothetical test based on correlation ratio (Eta) were two main statistical methods in this study. Cronbach's $\alpha$ coefficient for this test was measured 0.705 .

The study protocol was approved by the ethics committee of the Esfahan University of Medical Sciences and all participants gave an informed consent before enrollment.

\section{RESULTS}

The findings of this research consist of descriptive statistics including both qualitative and quantitative variables. Qualitative variables include job control, job demand, job strain (stressful working conditions caused by job demand, job control and the interactions between them), cigarette smoking and demographic data. Quantitative variables in this study included heart disease risk factors as well as age, which were presented by concepts such as number, percent, mean, standard deviation, degree of freedom and $p$ value.
The mean age of the study subjects was 42.52 years, BMI - 29.93, total cholesterol - 174.18, heart rate -79.33 and the systolic and diastolic blood pressure equaled 121.02 and 81.58, respectively. The results are contained in Table 1. As visible in Table 2, there is a significant relationship between age, job control and demand $(p=0.00<0.05)$. The frequency distribution of individuals with the mean age of 30-40 year has been higher among jobs characterized by high job demand and low job control.

A significant relationship also exists between BMI and job control and demand $(\mathrm{p}=0.01<0.05)$. Among the weighted population (BMI: 25-60), there were more people with a fairly higher job demand and low job control.

There is a significant relationship between the heart rate and job control and demand $\left(\mathrm{Chi}^{2}=145.07, \mathrm{p}<0.001\right)$. As presented in the Table above, the frequency of subjects with a high heart rate (above 90 ) was the highest (10.2\%) among the individuals with fairly high job demand and low job control, while the lowest frequency (1.4\%) was observed among the subjects with more reasonable job control and demand. It is noteworthy that more information is needed for an accurate judgment on increased heart rate (for example regular or irregular tachycardia) due to job strain (job control and demand). According to Table 2, a significant relationship was found between cigarette smoking and the job strain $\left(\mathrm{Chi}^{2}=35.65, \mathrm{p}<0.001\right)$. Moreover, among heavy smokers, the frequency distribution of the persons with high job demand and low job control was interestingly

Table 1. Mean (standard deviation) of quantitative variables in a sample of 500 workers at a petrochemical plant in Iran

\begin{tabular}{lcccccc}
\hline \multicolumn{1}{c}{ Parameters } & $\begin{array}{c}\text { Age } \\
(\text { years })\end{array}$ & $\begin{array}{c}\text { Total cholesterol } \\
(\mathrm{mg} / \mathrm{dl})\end{array}$ & Heart rate & BMI & $\begin{array}{c}\text { SBP } \\
(\mathrm{mmHg})\end{array}$ & $\begin{array}{c}\text { DBP } \\
(\mathrm{mmHg})\end{array}$ \\
\hline $\mathrm{M}$ & 42.52 & 174.18 & 79.33 & 29.93 & 121.02 & 81.58 \\
SD & 11.67 & 29.51 & 9.33 & 7.32 & 15.23 & 12.30 \\
Minimum & 22.00 & 111.00 & 60.00 & 19.00 & 100.00 & 40.00 \\
Maximum & 64.00 & 290.00 & 99.00 & 62.00 & 160.00 & 100.00 \\
\hline
\end{tabular}

$\mathrm{M}$ - mean; SD - standard deviation; BMI - body mass index.

SBP - systolic blood pressure; DBP - diastolic blood pressure. 
higher (10.6\%) among than non-smokers (6.4\%) and social smoker (9\%). Among non-smokers (or social smokers) the frequency distributions of the subjects with low job strain were higher (non-smokers: $12.2 \%$ and occasional smokers: $17.8 \%$ ) than among heavy smokers (3.8\%).

Based on Table 3 it can be stated that there is a significant relationship between systolic and diastolic arterial blood pressure and job strain. One-hundred thirty workers were exposed to fairly high job strain (high job demand and low job control) where:
- $27(20.8 \%)$ out of 29 workers $(22.3 \%)$ have blood pressure of $12 / 9$,

- $23(17.7 \%)$ out of 33 workers $(25.4 \%)$ have blood pressure of $13 / 10$,

- $12(9.2 \%)$ out of 18 workers $(13.8 \%)$ have blood pressure of $14 / 10$,

- $9(6.9 \%)$ out of 22 workers $(16.9 \%)$ have blood pressure of $15 / 10$,

- $8(6.2 \%)$ out of 19 workers $(14.6 \%)$ have blood pressure of $16 / 10$.

Table 2. The prevalence of job stress and the relationship with BMI, heart rate, smoking and age

\begin{tabular}{|c|c|c|c|c|}
\hline \multirow[t]{2}{*}{ Variables } & \multicolumn{3}{|c|}{$\begin{array}{l}\text { Job strain (high demand, low control) } \\
\qquad(\mathrm{N}=500) \\
\mathrm{n}(\%)\end{array}$} & \multirow[t]{2}{*}{ Data analysis results } \\
\hline & low & moderate & relatively high & \\
\hline BMI & & & & $\mathrm{Chi}^{2}=38.371$ \\
\hline$\leq 25$ & $50(10.0)$ & $56(11.2)$ & $50(10.0)$ & $p=0.01$ \\
\hline $25-30$ & $44(8.8)$ & $64(12.8)$ & $63(12.6)$ & $\mathrm{M}=79.3380$ \\
\hline$\geq 30$ & $75(15.0)$ & $81(16.2)$ & $17(3.4)$ & $\mathrm{SD}=7.32685$ \\
\hline total & $169(33.8)$ & $201(40.2)$ & $130(26.0)$ & \\
\hline Heart rate & & & & $\mathrm{Chi}^{2}=145.078$ \\
\hline $60-70$ & $60(12.0)$ & $53(10.6)$ & $5(1.0)$ & $\mathrm{df}=6$ \\
\hline $70-80$ & $73(14.6)$ & $93(18.6)$ & $25(5.0)$ & $\mathrm{p}=<0.001$ \\
\hline $80-90$ & $29(5.8)$ & $44(8.8)$ & $49(9.8)$ & $\mathrm{M}=79.3380$ \\
\hline$\geq 90$ & $7(1.4)$ & $11(2.2)$ & $51(10.2)$ & $\mathrm{SD}=9.3377$ \\
\hline total & $169(33.8)$ & $201(40.2)$ & $130(26.0)$ & \\
\hline Smoking consumption & & & & $\mathrm{Chi}^{2}=35.652$ \\
\hline never & $61(12.2)$ & $57(11.4)$ & $32(6.4)$ & $\mathrm{df}=4$ \\
\hline rarely & $89(17.8)$ & $96(19.2)$ & $45(9.0)$ & $\mathrm{p}=0.001$ \\
\hline often & $19(3.8)$ & $48(9.6)$ & $53(10.6)$ & $\mathrm{M}=0.9400$ \\
\hline total & $169(33.8)$ & $201(40.2)$ & $130(26.0)$ & $\mathrm{SD}=0.73313$ \\
\hline \multicolumn{5}{|l|}{ Age (years) } \\
\hline $20-30$ & $37(7.4)$ & $45(9.0)$ & $16(3.2)$ & $\mathrm{Chi}^{2}=30.941$ \\
\hline $30-40$ & $34(6.8)$ & $35(7.0)$ & $49(9.8)$ & $\mathrm{df}=8$ \\
\hline $40-50$ & $52(10.4)$ & $50(10.0)$ & $31(6.2)$ & $\mathrm{p}<0.001$ \\
\hline $50-60$ & $32(6.4)$ & $41(8.2)$ & $28(5.6)$ & $\mathrm{M}=42.5200$ \\
\hline$\geq 60$ & $14(2.8)$ & $30(6.0)$ & $6(1.2)$ & $\mathrm{SD}=11.67348$ \\
\hline total & $169(33.8)$ & $201(40.2)$ & $130(26.0)$ & \\
\hline
\end{tabular}

Abbreviations as in Table 1. 
Table 3. Eta coefficient and the relationship between high job demand and low job control with systolic and diastolic blood pressure

\begin{tabular}{llc}
\hline Job strain & Variable hypertension & Eta \\
\hline Low & systole & 0.527 \\
& diastole & 0.405 \\
Moderate & systole & 0.559 \\
& diastole & 0.442 \\
Relatively & systole & 0.684 \\
high & diastole & 0.696 \\
\hline
\end{tabular}

Eta - correlation ratio.

As stated for data frequency, regarding Blood Pressure, a considerable number of workers had High Normal BP (12/9 and 13/10) and it can be concluded that stressful work situations have considerable impact on the increase in blood pressure. There is also a significant relationship between the serum total cholesterol value and job control $(\mathrm{Eta}=0.469)$. However, this relationship is not very strong.

\section{DISCUSSION}

In this study, the relationship between job demand and control and their related cardiovascular disease risk factors were determined. For this purpose, 500 Staff of Esfahan Petrochemical Company (the total factory staff excluding those who changed their job positions since 2007 and/or were not willing to participate in the study, were asked to respond to the research questionnaires. Their personal health records were also investigated. Taking into consideration the inferential analysis of data and the results obtained from Tables 2 and 3, it was determined that job control and demand are significantly related to heart disease risk factors. As shown in Table 2, there is a significant relationship between the quantitative variable of age $\left(\mathrm{Chi}^{2}=30.941, \mathrm{p}<0.05\right)$ and the risk factors of BMI $\left(\mathrm{Chi}^{2}=38.371, \mathrm{p}<0.00\right)$, heart rate $\left(\mathrm{Chi}^{2}=145.078\right.$ and $\mathrm{p}<0.05)$, cigarette smoking $\left(\mathrm{Chi}^{2}=35.652, \mathrm{p}<0.05\right)$ and job stressors, i.e. low job control and high job demand.
The next variable related to job control and demand with a rather high chi-squared statistic is the age of the staff. The subjects aged 30-40 years have more job stressors than others. It should be mentioned that most of these subjects are engaged in jobs with high job demand and low job control. Taking into consideration BMI risk factors, the subjects were weighted due to high strain and here the chi-square is almost high indicating that there is a strong relationship between the experience of perceived stressors at work (high job demand and low job control) and BMI. The findings of this research are in agreement with the results obtained by Lundberg in 2003 showing a significant relationship between the perceived stress and its subsequent physiologic responses [14].

Moreover, a significant relationship was found between the risk factor of cigarette smoking and high job demand and low job control $\left(\mathrm{Chi}^{2}=35.65\right)$, namely some workers started smoking when they entered the factory workforce, while others increased their cigarette consumption.

Fundamentally, cigarette smoking and the growing number of smoked cigarettes make a behavioral disorder caused by mental pressures due to workload and such behavioral disorder can be a heart disease risk factor for the smokers.

In this regard, the findings of this research confirm the results of the studies conducted by De Lange in 2004 and Bishop et al. in 2003 [15,16]. The results also fit the hypothesis that a relationship exists between job strain (on the basis of high job demand) and a worker's low control on his/her work performance as well as the impact of these two factors on the worker's behavioral characteristics, which leads to the emergence of heart disease risk factors $[15,16]$. Among the quantitative variables, the value of the chisquared statistic for heart rate is higher than all other mentioned variables, however, since we do not know whether the increase in the workers' heart rate occurred due to direct reasons or indirect reasons, we cannot judge on the issue of tachycardia while we do not know whether stressful working conditions in petrochemical staff resulted in 
the increased heart rate or not. However, one of the main causes of "increasing heart rate" is the worker's stress and in fact, "increasing heart rate" is firstly emerged as a result of high job demand and low job control followed by another risk factor, arterial blood pressure. As depicted in Table 3, there is a significant relationship between high systolic and high diastolic blood pressure and high job demand and low job control.

The highest frequency distribution of the population indicates that the increase in arterial blood pressure was seen in a group with high job demand and low job control, in other words, those having been exposed to job strain. As illustrated in Table 3, the more the subject experiences stressful working conditions, the more he/she will develop hypertension. Thus, Eta coefficient is fairly high in the strain group, (systolic blood pressure: Eta $=0.686$ ) (diastolic blood pressure: Eta $=0.696$ ).

There was also a relationship between the serum total cholesterol value and stress $($ Eta $=0.469)$ however, this relationship was not very strong in this study.

The above findings obtained in this research are in agreement with the results obtained by Stepto et al. in 2007 and 2000 concerning the relationship between job stress with the increased concentration of free cholesterol early in the morning and the increase in the probable occurrence of the subsequent heart attack $[17,18]$.

Also, the findings of this research confirm the outcomes obtained by Steenland et al. in 1997 who found that the increased mental and physical job demand is consistent with changes in the workers' reactivated and improved concentrations of cortisol and catecholamines [19].

When considering the results of this research, it is suggested to put more focus on the psychological variables in organizations. Job redesign should be taken into consideration to increase individual control of the work processes and thus the individuals' social welfare as well as organization productivity. Education programs should be held in order to help the groups exposed to rather high job pressure (high job demand, low job control); the individuals' personal and physical characteristics should be taken into account upon their employment in order to increase staff motivation as well as their physical and, particularly, heart health and, consequently, to decrease heart disease risk factors such as blood pressure, BMI, increasing heart pressure, cholesterol, and cigarette smoking, and/or at least to minimize the extent of their occurrence.

In a study conducted in Norway, the relationship between job demand, job resources and burnout was examined among 223 Norwegian police officers. The overall level of burnout was low among police officers compared to other occupational groups tested in Norway. Both job demand and job resources were related to burnout. Burnout predicted individual outcomes, such as psychosomatic complaints and satisfaction with life, as well as work outcomes, such as job satisfaction, intention to quit, and organizational commitment [10]. This study is unique in that it applies psychosocial ratings of demand and control that are objective, assigned by occupational health professionals familiar with individual jobs, evaluates heart disease risk factors using readily available health claims data, and uses an acceptable design with a cohort of petrochemical workers. Current research also builds upon previous work that has tried to determine the risk related with workplace psychological demand and health control.

\section{ACKNOWLEDGMENT}

We would like to express our sincere gratitude to Farzan Institute for Research \& Technology for technical assistance.

\section{REFERENCES}

1. Karasek RA, Theorell T. Health Work. New York: Basic Books; 1990.

2. Karasek RA. Job demands, job decision latitude, and mental strain: Implications for job redesign. Adm Sci Q. 1979;24(2):285-307. 
3. Ausner-Dorsch H, Eaton WW. Psychosocial work environment and depression: Epidemiologic assessment of the demand-control model. Am J Public Health. 2000;90(11): 1765-70.

4. Bildt C, Michelsen H. Gender differences in the effects from working conditions on mental health: A 4-year follow-up. Int Arch Occup Environ Health. 2002;75(4):252-8.

5. Virtanen M, Honkonen T, Kivimaki M, Ahola K, Vahtera J, Aromaa A, et al. Work stress, mental health and antidepressant medication findings from the health 2000 study. J Affect Disord. 2007;98(3):189-97.

6. Fortney J, Rushton G, Wood S, Zhang L, Xu S, Dong F, et al. Community-level risk factors for depression hospitalization. Adm Policy Ment Health. 2007;34(4):343-52.

7. Belkic K, Schnall P, Ugljesic M. Cardiovascular evaluation of the worker and workplace: A practical guide for clinicians. In: Schnall P, Belkic K, Landsbergis P, Baker D, editors. The workplace and cardiovascular disease. Philadelphia: Hanley \& Belfus; 2000. p. 163-88.

8. Karasek RA, Theorell T, Schwartz JE, Schnall PL, Pieper CF, Michela JL. Job characteristics in the US health examination survey (HES) and the health and nutrition examination survey (HANES). Am J Public Health. 1988;78(8):910-8.

9. Mathers CD, Loncar D. Projections of global mortality and burden of disease from 2002 to 2030. PLoS Med. 2006;3:e442.

10. Martinussen M, Richardsen AM, Burke RJ. Job demands, job resources, and burnout among police officers. J Criminal Justice. 2007;35(3):239-49.

11. Rosamond W, Flegal K, Furie K, Go A, Greenlund K, Haase N. Heart disease and stroke statistics 2008 update: A report from the American Heart Association statistics committee and stroke statistics subcommittee. Circulation. 2008;117(4):e25-146.

12. Karasek R, Baker D, Marxer F, Ahlbom A, Theorell T. Job decision latitude, job demands, and cardiovascular disease: A prospective study of Swedish men. Am J Public Health. 1981;71(7):694-705.

13. Wall TD, Jackson PR, Mullarkey S, Parker SK. The demandcontrol model of job strain: A more specific test. J Occup Organ Psychol. 1996;69:153-66.

14. Lundberg U. Catecholamines and Environmental Stress. Department of Psychology and Centre for Health Equity Studies (CHESS), Stockholm University, for the Allostatic Load notebook. Last revised November, 2008 [cited 2010 Sept 1]. Available from URL: http://www.macses.ucsf.edu/research/ allostatic/catecholamine.php.

15. De Lange AH, Taris TW, Kompier MA, Houtman IL, Bongers PM. The very best of the millennium: longitudinal research and demand-control-(support) model. J Occup Health Psychol. 2003;8(4):282-305.

16. Bishop GD, Enkelmann HC, Tong EM, Why YP, Diong SM, Ang J, et al. Job demands, decisional control, and cardiovascular responses. J Occup Health Psychol. 2003;8(2):146-56.

17. Steptoe A, O’Donnell K, Badrick E, Kuman M, Marmot M. Neuroendocrine and inflammatory factors associated with positive effect in healthy men and women: The Whitehull II study. Am J Epidemiol. 2007;167(1):96-102.

18. Steptoe A, Cropley M, Griffith J, Kirschbaum C. Job strain and anger expression predict early morning elevations in salivary cortisol. Psychosom Med. 2000;62(2):286-92.

19. Steenland K, Johnson J, Nowlin SA. A Follow up study of job strain and heart disease among males in the NHANES1 population. Am J Ind Med. 1997;31(2):256-60.

This work is available in Open Access model and licensed under a Creative Commons Attribution-NonCommercial 3.0 Poland License - http://creativecommons.org/ licenses/by-nc/3.0/pl/deed.en. 